Research Paper:

\title{
Pain and Related Pre-Hospital Factors in Patients With Trauma: A Cross-Sectional Study
}

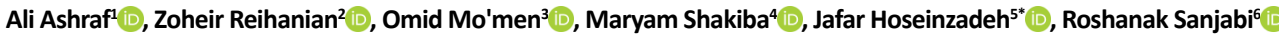

1. Assistant Professor of Anesthesia, Department of Anesthesia, Poursina Hospital, Guilan University of Medical Sciences, Rasht, Iran

2. Assistant Professor of Neurosurgery, Department of Neurosurgery, Poursina Hospital, Guilan University of Medical Sciences, Rasht, Iran

3. Assistant Professor of Orthopedics, Department of Orthopedics, Gorgan University of Medical Sciences, Golestan, Iran

4. Assistant Professor of Epidemiology, Poursina Hospital, Guilan University of Medical Sciences, Rasht, Iran

5. Resident of Neurosurgery, Department of Neurosurgery, Poursina Hospital, Guilan University of Medical Sciences, Rasht, Iran

6. General Physician, Poursina Hospital, Guilan University of Medical Sciences, Rasht, Iran

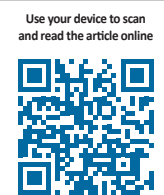

Citation: Ashraf A, Reihanian Z, Mo'men O, Shakiba M, Hoseinzadeh J, Sanjabi R. Pain and Related Pre-Hospital Factors in Patients With Trauma: A Cross-Sectional Study. Iran J Neurosurg. 2018; 4(1):25-34. http://dx.doi.org/10.32598/irjns.4.1.25

http://dx.doi.org/10.32598/irjns.4.1.25

Funding: See Page 33

(c) Copyright: The Author(s)

Article info:

Received: 20 September 2017

Accepted: 28 November 2017

Available Online: 01 January 2018

Keywords:

Severity, Pain, Trauma,

Prehospital

\section{A B S TRACT}

Background and Aim: Pain is an experience often caused by tissue damage and is proportional to the severity of the injury. The role of underlying factors in severity of the pain such as prehospital factors have been discussed in some investigations. The current study aimed to assess the effect of different parameters on pain severity in patients with trauma.

Methods and Materials/Patients: The current descriptive, cross-sectional study was conducted fully conscious 270 fully patients with trauma admitted to Poursina Hospital in Rast, Guilan, Iran, in 2016. They were assessed in terms of demographic and pre-hospital factors as well as mechanism and severity of trauma based on verbal rating scale.

Results: Linear regression analysis demonstrated that among various factors like age, sex, level of education, opium dependence, vehicle type, ventilation, blood pressure, pulse rate, mechanism of trauma, and type of trauma, the highest severity of pain was pertaining to the type of trauma such as multiple trauma and large bone fracture with mean scores of 9.26 and 9.13, respectively. It also revealed that among these parameters, mechanism of trauma, type of trauma, transfer time, type of vehicle, and pulse rate were significantly associated with the severity of the pain.

Conclusion: The current study showed that increasing the quality of vehicle, decreasing the transfer time, and paying more attention to hemodynamic factors such as pulse rate, blood pressure, use of analgesic agents, and immobilization of damaged tissue can diminish the severity of pain in patients with trauma.

\section{* Corresponding Author:}




\section{Introduction}

ain is an experience often caused by tissue damage, and is proportional to the severity of the injury. Prior research suggests that pain is usually associated with hemodynamic changes, triggering stressful hormones, catecholamines, and vasoactive agents, which can lead to changes in blood pressure and increased sympathetic tone. These changes alter the clinical course of the disease, interfere with the assessment of therapeutic responses, and ultimately affect the mortality rate of the patients [1]. Pain plays an important role in patients' quality of life after experiencing the initial injury and during the chronic phase after the trauma. Furthermore, a number of authors have recognized that the average pain during an accident is usually accompanied with some types of mental illnesses such as PostTraumatic Stress Disorder (PTSD) or depression [2]

Some authors have assessed the development of some underlying factors that may affect the average pain, including demographic and individual characteristics of the patient, as well as prehospital care, like the duration and type of patient transfer to hospital [3]. Precise identification of these aspects and assessment of their influence on patient's mean pain can be an indicator to explain the prehospital care elements and predict the mean pain. To conclude, the mean pain score could be used in appropriate and early therapeutic interventions for patients.

The Rasht Poursina Hospital accident and emergency department, as a trauma referral center in Guilan and neighboring provinces, admits a significant number of patients every day. Therefore, investigating the abovementioned factors and applying the results of the evaluation can be effective in improving the quality of care for patients referred to this hospital and similar health care centers.

The current study aimed to explore the mean score of pain in patients with trauma who were referred to Poursina Hospital in 2016. Subjects were selected based on traumatic injury, type of transporting vehicle, intraocular air temperature, age, sex, education, blood pressure, heart rate, and histories of drug use. Moreover, we evaluated the effect of prehospital variables on average pain score, using results of the current study to predict the factors affecting the mean score of pain, and eventually, utilized the information to determine the control protocols of patients with trauma. According to a study in 2016 by Prastika et al. [4], the mean score of pain and its effect on patient's sleep, activity, and walking were described as moderate to severe in order to determine the control protocol of patients with trauma (the mean pain score based on Numeric Pain Rating (NPR) or Brief Pain Inventory (BPI).

In Gerhardt et al. study, a positive correlation between prehospital pain and prescribing analgesic drugs before hospitalization, and after admission pain score was confirmed [5]. Another investigation by Paydar et al. demonstrated that prescribing analgesic drugs had a positive impact on the improvement of patient's pain, with no negative effects on their diagnostic and therapeutic measures [6].

\section{Methods and Materials/Patients}

\section{Sampling}

The current descriptive, cross-sectional study was conducted on injured patients with complete level of consciousness. Based on the Blackman et al. study results, the mean (SD) pain score was 5.5(1.3) on 216 patients with precision estimate of 4.2 [7]. But with taking into account 50 samples per 10 predictors, the final sample size was calculated as 266 persons using the following formula:

$$
n=\frac{(P-1) P\left(Z \frac{1-a}{2}\right)^{2}}{e^{2}}
$$

In the current study, the mean pain induced by trauma was measured according to the considered variables.

\section{Inclusion criteria}

Inclusion criteria of the current study samples consisted of traumatic patients with the Glasgow coma score of 15 and able to determine the mean pain score (verbally or manually) in accordance with the criteria for scoring 0 to 10 Verbal Numerical Rating Scale (VNRS).

\section{Exclusion criteria}

Subjects who passed away during or after the first 24 hours of the occurrence of trauma, or lost their verbal or manual ability were excluded from the investigation.

\section{Data collection}

For this study, we analyzed the data collected from a researcher-developed questionnaire, designed to evaluate the mean level of pain. The main data in this work consisted of the severity of pain. The questionnaire 
consisted of two parts: first, personal features including demographic indicators (i.e. age, sex, level of education, histories of drug use) and biological features (i.e. blood pressure, heart rate); second, prehospital variables (i.e. type of transfer vehicle, temperature inside the transfer vehicle, and total time in transfer), types of trauma mechanisms (i.e. falling, fires, road incidents, pedestrian accidents, car-motorcycle accidents), severity of trauma, and type of trauma (i.e. large bone fracture, burns, soft tissue injuries, stiffness, cuts, and tissue lesion).

Severity of pain was determined based on a 10-point Likert-type Verbal Numerical Rating Scale (VNRS), on patient's arrival to the trauma center. In addition, the patient's vital signs were measured and recorded at the time of admission and thereupon.

\section{Statistical analysis}

The collected data were analyzed using descriptive statistics of the absolute, relative, mean and Standard Deviation (SD), also inferential statistics, including t test and Analysis of Variance (ANOVA) in SPSS V. 23. The differences were determined by the Bonferroni post hoc test. We also utilized Kolmogorov-Smirnov test to evaluate normality of data. A multivariate linear regression model was used to estimate the effect of each underlying variable on the mean pain score. We considered $\mathrm{P}<0.05$ as the level of significance.

\section{Results}

The current study was performed on 270 patients with the mean (SD) age of $40(42.1)$ year (age range: 25-49 years).

Table 1 shows distribution of patients based on their underlying characteristics. Most of the study participants were male $(n=177)$, with the education level of below high-school diploma. Of all subjects, 89 suffered from substance dependence. The mean score of pain in multiple injuries, and the fracture of large bones were obtained as 9.26 and 9.13 , respectively $(P<0.05)$ in respect of the trauma type (Figure 1).

The highest mean pain score was reported for less than 15 minutes (score=2.8) for the total time in patients transfer from the incident scene to the hospital, which was significantly different with the time groups of 15-30 minutes and $>60$ minutes $(P<0.05)$, although no significant difference was observed between the groups of 30-60 minutes and other time intervals (Figure 2).

Among trauma mechanisms, the highest mean pain score was related to motorcycle accidents (score=5.8), which its mean score was significantly different compared to other types of mechanisms $(P<0.05)$ except for the motorcycle and car crashes and, pedestrian-car incidents (Figure 3).

The highest mean score of pain was reported for the group transferred by the ambulances, compared to those transferred by private cars $(P<0.05)$; nevertheless, there was no significant difference between these groups (Figure 4). There was a significant difference between the studied patients in terms of hypotension and normal level of blood pressure.

As demonstrated in Tables 2 and $3, R^{2}$ equals 0.72 , which means that the pain score changes were predictable by the model. According to the multivariate model, a statistically significant relationship exist between the mean score of pain and trauma type variables, patient's transfer pattern, trauma mechanism, and heart rate, after adjusting the effect of other variables. Our results showed a significant rise in the mean score of pain following increased trauma severity. Hence, the pain score of patients with large bone fracture was 2.70 units

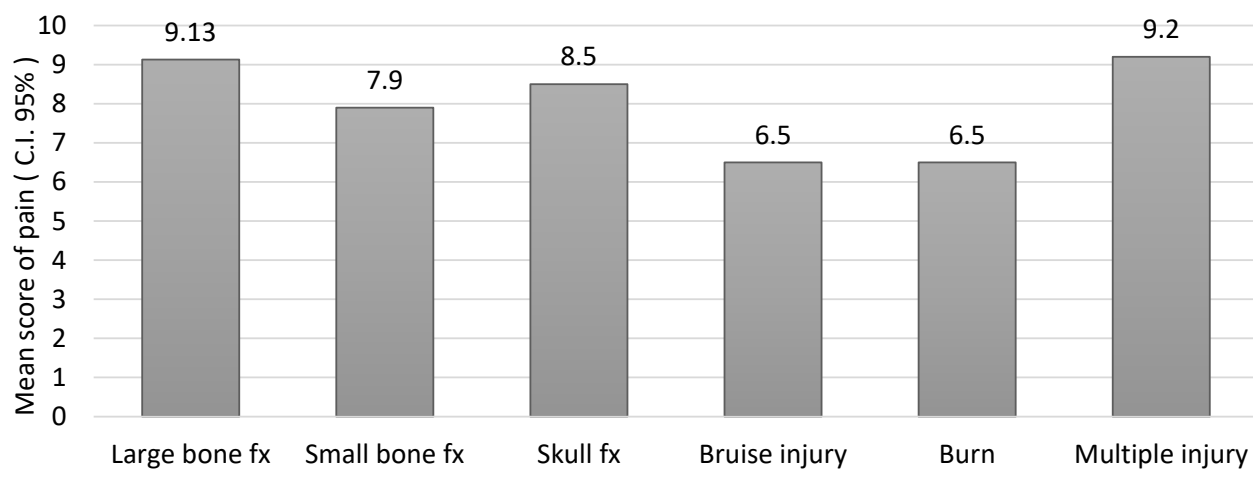

Figure 1. The mean pain score in respect of the type of trauma 
Table 1. Distribution of patients' characteristics

\begin{tabular}{|c|c|c|c|}
\hline \multicolumn{2}{|c|}{ Characteristics } & \multirow{2}{*}{$\begin{array}{l}\text { No. } \\
177\end{array}$} & \multirow{2}{*}{$\begin{array}{l}\% \\
65\end{array}$} \\
\hline & Male & & \\
\hline sex & Female & 93 & 35 \\
\hline \multirow{4}{*}{ Age (y) } & $<25$ & 53 & 19.2 \\
\hline & $25-49$ & 131 & 48.6 \\
\hline & $50-60$ & 43 & 16 \\
\hline & $>60$ & 44 & 16.2 \\
\hline \multirow{3}{*}{ Level of Education } & Below high-school diploma & 120 & 44 \\
\hline & High-school Diploma & 80 & 29 \\
\hline & Higher education & 70 & 25 \\
\hline \multirow{2}{*}{ Type of transfer vehicle } & Ambulance & 129 & 48 \\
\hline & Private car/motorcycle & 141 & 52 \\
\hline \multirow{4}{*}{ Total time in transfer ( $\mathrm{min})$} & $<15$ & 66 & 24.5 \\
\hline & $15-30$ & 122 & 48 \\
\hline & $30-60$ & 48 & 18 \\
\hline & $>60$ & 34 & 12.5 \\
\hline \multirow{2}{*}{ Vehicle air conditioning } & On & 181 & 67 \\
\hline & Off & 89 & 33 \\
\hline \multirow{5}{*}{ Trauma mechanism } & Car accident & 87 & 32 \\
\hline & Motorcycle accident & 56 & 21 \\
\hline & Pedestrian-car accident & 45 & 17 \\
\hline & Falling & 33 & 12 \\
\hline & Miscellaneous & 49 & 18 \\
\hline \multirow{5}{*}{ Type of trauma } & Large bone fracture & 30 & 11 \\
\hline & Small bone fracture & 18 & 6 \\
\hline & Skull fracture & 23 & 8.5 \\
\hline & Burning, bruise & 130 & 48 \\
\hline & Multiple trauma & 69 & 25 \\
\hline \multirow{3}{*}{ Systolic blood pressure $(\mathrm{mm} \mathrm{Hg})$} & $<100$ & 91 & 33 \\
\hline & $100-140$ & 172 & 73 \\
\hline & $>140$ & 7 & 2 \\
\hline \multirow{2}{*}{ Heart rate (bpm) } & $60-90$ & 124 & 46 \\
\hline & $>90$ & 146 & 54 \\
\hline \multirow{2}{*}{ Opium dependence } & Yes & 89 & 34 \\
\hline & No & 181 & 66 \\
\hline
\end{tabular}


Table 2. Comparison of the mean pain score based on the study variables

\begin{tabular}{|c|c|c|c|c|}
\hline \multicolumn{2}{|c|}{ Characteristics } & \multirow{2}{*}{$\begin{array}{l}\text { No. } \\
177\end{array}$} & \multirow{2}{*}{$\begin{array}{c}\text { Mean (SD) Pain Score } \\
7.77(1.14)\end{array}$} & \multirow{3}{*}{$\begin{array}{c}\mathbf{P} \\
0.594\end{array}$} \\
\hline Sx & Male & & & \\
\hline ת & Female & 93 & $7.88(1.55)$ & \\
\hline \multirow{4}{*}{ Age (y) } & $<25$ & 52 & $7.88(1.54)$ & \multirow{4}{*}{0.978} \\
\hline & $25-49$ & 131 & $7.82(1.54)$ & \\
\hline & $50-60$ & 43 & 7.73(1.49) & \\
\hline & $>60$ & 44 & $7.81(1.50)$ & \\
\hline \multirow{3}{*}{ Level of education } & Below high-school diploma & 120 & $7.81(1.58)$ & \multirow{3}{*}{0.030} \\
\hline & High-school Diploma & 80 & $7.59(1.38)$ & \\
\hline & Higher education & 70 & 7.64(1.49) & \\
\hline \multirow{2}{*}{ Type of the transfer vehicle } & Ambulance & 136 & $8.1(1.25)$ & \multirow{2}{*}{0.005} \\
\hline & Car/ motorcycle & 141 & $7.5(1.66)$ & \\
\hline \multirow{4}{*}{ Total time in transfer (min) } & $<15$ & 66 & $8.24(1.38)$ & \multirow{4}{*}{0.035} \\
\hline & $15-30$ & 122 & 7.69(1.49) & \\
\hline & $30-60$ & 48 & $7.79(1.50)$ & \\
\hline & $>60$ & 34 & $7.40(1.66)$ & \\
\hline \multirow[b]{2}{*}{ Vehicle air conditioning } & On & 181 & $7.44(1.61)$ & \multirow[b]{2}{*}{0.005} \\
\hline & Off & 89 & $7.99(1.42)$ & \\
\hline \multirow{5}{*}{ Trauma mechanism } & Car accident & 87 & $8.05(1.5)$ & \multirow{5}{*}{0.001} \\
\hline & Motorcycle accident & 56 & $8.5(1.36)$ & \\
\hline & Pedestrian-car accident & 45 & $7.32(1.51)$ & \\
\hline & Falling & 33 & $7.25(1.50)$ & \\
\hline & Other items & 49 & $7.41(1.28)$ & \\
\hline \multirow{5}{*}{ Type of trauma } & Large bone fracture & 30 & $9.13(0.66)$ & \multirow{5}{*}{0.006} \\
\hline & Small bone fracture & 18 & $7.9(1.04)$ & \\
\hline & Skull fracture & 23 & $8.5(0.59)$ & \\
\hline & Burning, bruise & 130 & $6.5(1.03)$ & \\
\hline & Multiple & 69 & $9.2(0.54)$ & \\
\hline \multirow{3}{*}{ Systolic blood pressure (mm Hg) } & $<100$ & 91 & $8.63(1.29)$ & \multirow{3}{*}{0.001} \\
\hline & $100-140$ & 172 & $7.36(1.44)$ & \\
\hline & $>140$ & 7 & $8.07(0.97)$ & \\
\hline \multirow{2}{*}{ Heart rate (bpm) } & $60-90$ & & $7.5(1.65)$ & \multirow[b]{2}{*}{0.003} \\
\hline & $>90$ & & $8.06(1.31)$ & \\
\hline \multirow[b]{2}{*}{ Opium dependence } & Yes & 89 & \multirow[b]{2}{*}{$7.85(1.53)$} & \multirow[b]{2}{*}{0.712} \\
\hline & No & 181 & & \\
\hline
\end{tabular}




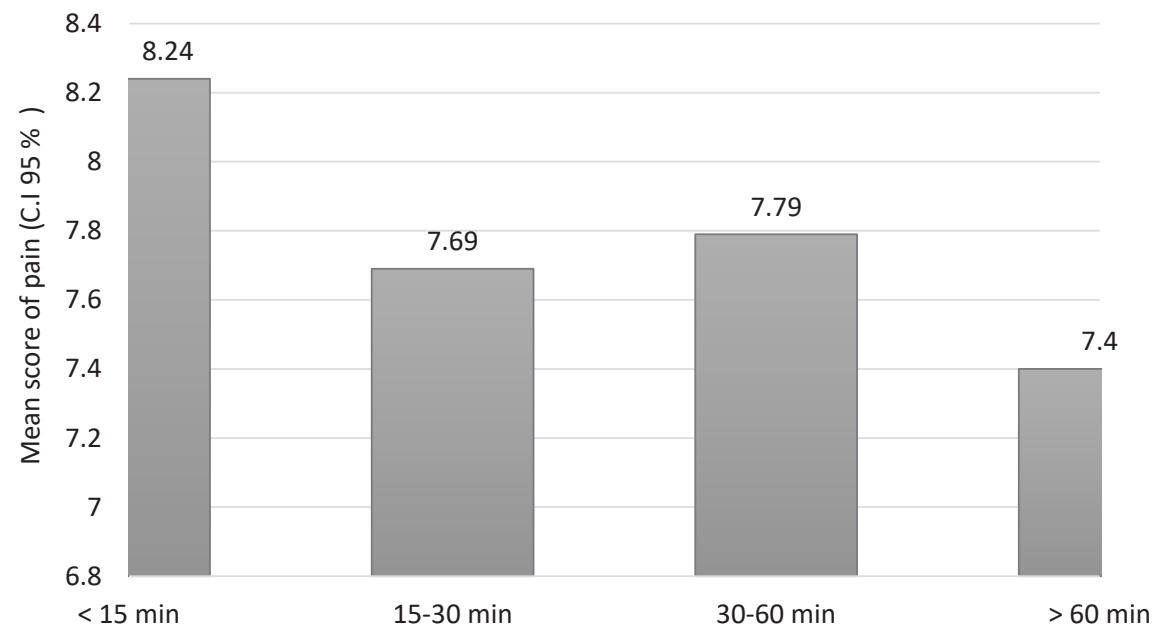

Figure 2. Comparison of the mean pain score in terms of the total time of patients's transfer to the hospital

higher than the subjects in the burning trauma group. The pain score of patients transported by car and motorcycle was $0.72 \%$ lower than the ones transferred by ambulance. The data regarding mechanism of trauma reveals significant differences in increased pain of falling cases compared to those suffering from other mechanisms of trauma. Our data also address that the mean pain of patients with tachycardia was 0.34 times higher than the subjects with normal heart rate.

\section{Discussion}

In the study conducted by Mohseni et al. in Poursina Hospital of Rasht [8], the mean age of the patients was reported as 35 years and the number of male and female patients was equal, which was in line with the results of the current study. Another study was done by Yeguiyan et al. in France [7], in which most of the partici- pants were male within the age range of 30-50 years. In the current investigation, our first two groups of study had the highest traumatic cases of traffic accidents; i.e. $39 \%$ of them had motorcycle accident and $32 \%$ experienced car crashes.

In addition, there were two groups of car crash incidents, followed by motorcycle and pedestrian-car accidents. Perhaps higher number of men and high incidence of trauma in the age range of 25-49 years were due to the fact that these groups were young and active, more exposed to social activities and more likely to be involved in accidents. This result correspands with previous studies, in terms of age range and sex $[9,10]$.

Prastika et al. reported moderate to severe mean pain score in patients with orthopedic and musculoskeletal trauma [4]. In a study on traumatic events by the Law

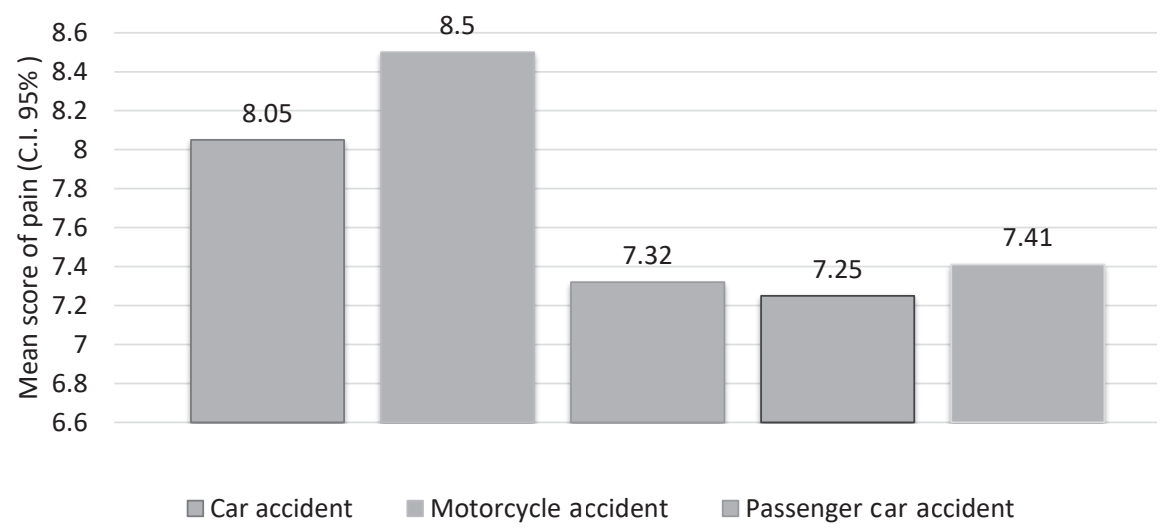

Figure 3. Comparision of mean pain scores due to trauma mechanism 


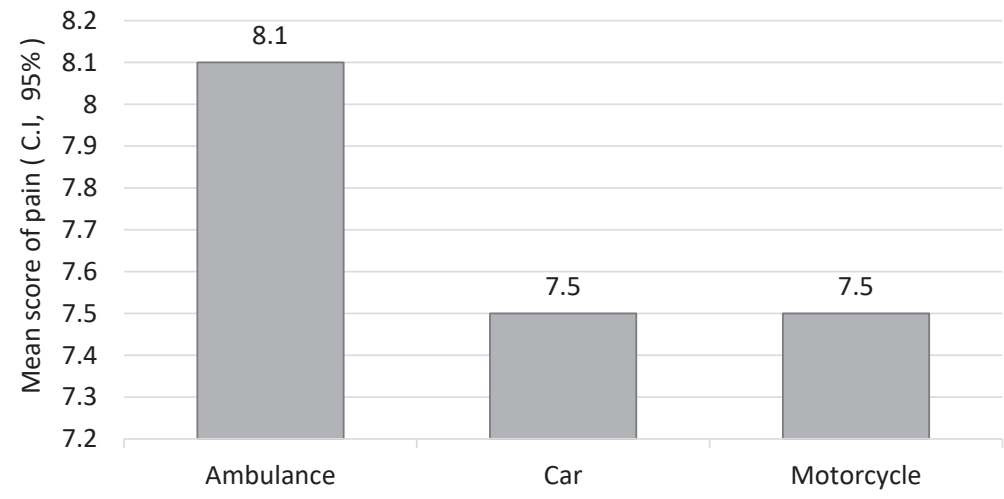

Figure 4. Comparison of mean pain score with respect to the patient transfer vehicle to the hospital

Enforcement Force of the Islamic Republic of Iran, the highest mean pain score was related to traumatic fractures [7]. According to the results of the present research, the highest mean score of pain was associated with musculoskeletal traumas as per following order: large bones fractures, small bones fractures, skull fractures, and penetrating traumas, which was in accordance with the findings of previous studies [3].

Our results indicate a higher mean pain score compared to similar other studies, which may be explained by the following reasons: first, pain severity was self-reported by the patients in our research, while in prior investigations, the pain intensity was reported by physicians and nurses [11-13]; second, misconceptions in some indigenous and regional groups; a they falsely believe that they can receive more attention from treatment centers in case of reporting higher mean pain rates; third, use of different analgesic drugs after trauma in various studies could be a determining factor in such differences. Based on the findings of the current study, most patients had normal systolic blood pressure, and although the two groups had a lower frequency with high and low blood pressures, the mean score of their pain severity was significantly higher than the normal range [14].

According to the results of previous studies on the total time in patient's transfer to the hospital [15-17], advantages of reducing this period is still ambiguous. Prior studied highlighted that indeterminable regional factors, ethnicity, different tastes in selecting the study population, different measurement tools, impact of different factors on outcomes, and so on may influence the research outcome [15]. A study by Dinh et al.

Table 3. The results of adjusted variables estimation in relation with the mean pain score by the multiple regression test

\begin{tabular}{|c|c|c|c|c|}
\hline \multicolumn{2}{|c|}{ Characteristics } & \multirow{2}{*}{$\begin{array}{c}\text { Beta Factor (Coefficient) } \\
\text { Reference }\end{array}$} & \multirow{2}{*}{$\begin{array}{c}95 \% \mathrm{Cl} \\
-\end{array}$} & \multirow{2}{*}{$\begin{array}{l}\mathbf{P} \\
-\end{array}$} \\
\hline & Male & & & \\
\hline sex & Female & -0.356 & $-0.029,0.150$ & 0.538 \\
\hline \multirow{4}{*}{ Age (y) } & $<25$ & Reference & - & - \\
\hline & $25-49$ & -0.003 & $-0.278,0.280$ & 0.98 \\
\hline & $50-60$ & 0.127 & $-0.245,0.500$ & 0.50 \\
\hline & $>60$ & 0.90 & $0.278,0.457$ & 0.63 \\
\hline \multirow{3}{*}{ Level of education } & Below high-school diploma & Reference & - & - \\
\hline & High-school diploma & 0.290 & $-0.001,0.510$ & 0.051 \\
\hline & Higher education & 0.109 & $-0.157,0.376$ & 0.42 \\
\hline \multirow{2}{*}{ Type of transfer vehicle } & Ambulance & Reference & - & - \\
\hline & Car/motorcycle & -0.27 & $-0.50,-0.06$ & 0.013 \\
\hline \multirow{2}{*}{ Vehicle air conditioning } & On & 0.006 & $-0.235,0.230$ & 0.970 \\
\hline & Off & - & - & - \\
\hline
\end{tabular}




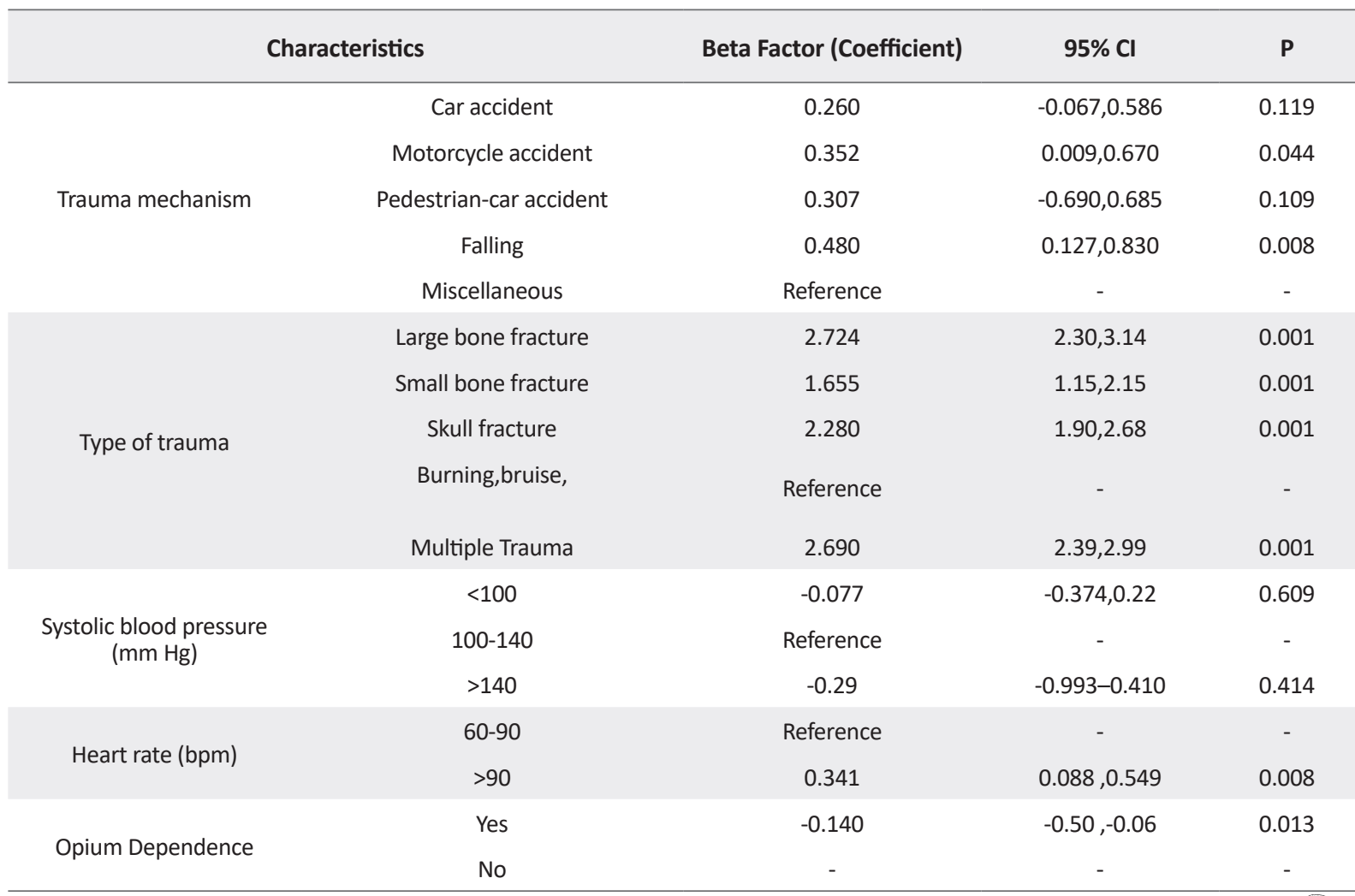

showed that each minute delay was associated with an increase of $0.2 \%$ in mortality, during the transfer of patients with head trauma which lasted more than 60 minutes [18].

In the current study, patients with trauma were often transferred to hospital in less than 30 minutes, and it was concluded that the duration of patient's transmission to the hospital, based on linear regression, had a significant impact on the mean score of pain. In addition, several studies confirmed that shortening the total time in transfer had a positive impact on reducing mortality in traumatic patients $[19,20]$.

In the current study, patients with ventilated vehicles had a lower mean pain score compared to others, but such difference was not found statistically significant. Most people with severe trauma were transferred to Poursina Hospital by ambulance, and patients with lower pain rates did not use ambulance and were taken to the hospital without ventilation or even with motor vehicles; hence, the higher mean score of pain in the group transferred with ambulance could have been expected. On the other hand, the group transferred with no ventilation and motor vehicles reported lower median score of pain due to less traumatic and non-intentional use of ambulance. Future studies should aim to replicate results and compare the mean pain score in vehicles equipped with ventilation, and perhaps more accurate indicator of the patient's transfer vehicle could be obtained.

Berben et al. reported that use of epinephrine, Nonsteroidal Anti-inflammatory Drugs benzodiazepines, and opium significantly reduced post-traumatic pain in patients [3]. In the present study, the mean pain sensation was measured in two groups of opium and non-opium dependents, which results did not differ significantly. A probable reason to such lack of difference might be due to the fact that opium was abused by the patients in the current study.

Unlike prior research studies, the current study solely examined patients with acute traumas (GCS $\geq 14$ ). As a result, there were some differences between analytical achievements of the current study and other investigations due to lack of examination of patients with trauma and reduced consciousness in them.

\section{Conclusion}

The current study investigated the mean score of pain in 270 patients with trauma referring to Poursina Hospi- 
tal in Rasht. The sample population included 171 men and 93 women with the mean age of 40 years. Variables of our study included age, sex, level of education, type of transfer, total time in transfer, trauma mechanism, type of trauma, substance dependence, and hemodynamic factors. Among these variables, type of trauma, transfer vehicle, traumatic mechanism, transferring time, and heart rate were significantly correlated with the mean score of pain. Based on the results of linear regression, most factors influencing the mean pain score in multiple injuries and fractures of large bones were measured as 9.26 and 9.13 , respectively.

It is recommended to examine the role of hemodynamic factors such as blood pressure and heart rate, and employ an acceptable pain assessment criterion in patients with reduced consciousness in the further studies.

Since trauma is a major cause of death and often affects the hemodynamic system, it is recommended that the pain be controlled that can be effective on hemodynamic parameters. Perhaps using pain relief methods including regurgitation block, injectable denture, and immobilization of the damaged limb could be helpful in this regard.

\section{Ethical Considerations}

\section{Compliance with ethical guidelines}

Ethics Committee of Guilan University of Medical Sciences has approved this paper with the ethics code of IR.GUMS.REC.1396.50.

\section{Funding}

This research did not receive any specific grant from funding agencies in the public, commercial, or not-forprofit sectors.

\section{Conflict of interest}

The authors declared that they have no conflict of interest.

\section{Acknowledgements}

The authors contribution is as follows: Ali Ashraf, Maryam Shakiba, Jafar Hosseinzadeh, and Roshanak Sanjabi: Drafting the article; Ali Ashraf, Zoheir Reihanian, Maryam Shakiba, and Omid Mo'men: Critically revising the article, reviewing submitted version of manuscript, approving the final version of the manuscript; Maryam Shakiba, Jafar Hosseinzadeh and Roshanak Sanjabi:
Data collecting; Jafar Hosseinzadeh and Roshanak Sanjabi: Conception and design.

\section{References}

[1] McMahon S, Koltzenburg M, Tracey I, Turk D. Textbook of pain New York: Elsevier; 2014.

[2] Miller RD, Eriksson LI, Fleisher LA, Wiener-Kronish JP, Cohen NH, Young WL. Miller's anesthesia. New York: Elsevier; 2018.

[3] Berben SA, Meijs TH, van Dongen RT, van Vugt AB, Vloet LC, Mintjesde Groot JJ, et al. Pain prevalence and pain relief in trauma patients in the Accident \& Emergency department. International Journal of the Care of the Injured. 2008; 39(5):578-85. [DOI: 10.1016/j.injury.2007.04.013] [PMID]

[4] Prastika D, Kitrungrote L, Damkliang J. Pain intensity and pain interference among trauma patients: A literature review. Belitung Nursing Journal. 2016; 2(6):131-139.

[5] Gerhardt RT, Reeves PT, Kotwal RS, Mabry RL, Robinson JB, Butler F. Analysis of prehospital documentation of injury-related pain assessment and analgesic administration on the contemporary battlefield. Prehospital Emergency Care. 2016; 20(1):37-44. [DOI:10.3109 /10903127.2015.1051683] [PMID]

[6] Paydar Sh, Alizadeh M, Taheri R, Mousavi SM, Niakan H, Hoseini N, et al. The Prevalence of Pain and the Role of Analgesic Drugs in Pain Management in Patients with Trauma in Emergency Department. Academic Journal of Surgery. 2015; 2(3-4):45-51.

[7] Blackman VS, Cooper BA, Puntillo K, Franck LS. Prevalence and predictors of prehospital pain assessment and analgesic use in military trauma patients, 2010-2013. Prehospital Emergency Care. 2016; 20(6):737-751. [PMID] [DOI:10.1080/10903127.2016.1182601]

[8] Mohseni M, Khaleghdoost Mohammadi T, Adib M, MohtashamAmiri Z, Yosefzadeh S, Kuchakinejad L, et al. [Emergency nervous system and related factors in hospital with traumatic patients (Persian)]. Journal of Health and Care. 2014; 16(1):55-65.

[9] Naghavi M, Shahraz S, Bhalla K, Jafari N, Pourmalek F, Bartels D, Puthenpurakal JA, Motlagh ME. Adverse health outcomes of road traffic injuries in Iran after rapid motorization. Archives of Iranian Medicine. 2009; 12(3):284-94. [PMID]

[10] Zargar M, Khaji A, Karbakhsh M. Pattern of motorcycle-related injuries in Tehran, 1999 to 2000: a study in 6 hospitals. Eastern Mediterranean Health Journal. 2006; 12(1-2):81-7. [PMID]

[11] Guru V, Dubinski I. The patient versus caregiver perception of acute pain in the emergency department. The Journal of Emergency Medicine. 2000; 18(1):7-12. [DOI:10.1016/S07364679(99)00153-5]

[12] Salmon P, Manyande A. Good patients cope with their pain: postoperative analgesia and nurses' perceptions of their patients' pain. The Journal of International Association for the Study of Pain. 1996; 68(1):63-8. [DOI:10.1016/S0304-3959(96)03171-5]

[13] Bijur PE, Bérard A, Esses D, Schechter C, Gallagher EJ. Lack of Influence of patient self-report of pain intensity on administration of opioids for suspected long-bone fractures. The Journal of Pain 2006; 7(6):438-44. [DOI:10.1016/j.jpain.2006.01.451] [PMID] 
[14] Browne LR, Studnek JR, Shah MI, Brousseau DC, Guse CE, Lerner EB. Prehospital opioid administration in the emergency care of injured children. Prehospital Emergency Care. 2016; 20(1):59-65. [DO I:10.3109/10903127.2015.1056897] [PMID]

[15] Newgard CD, Schmicker RH, Hedges JR, Trickett JP, Davis DP, Bulger EM, et al. Emergency medical services intervals and survival in trauma: assessment of the "golden hour" in a north American prospective cohort. Annals of Emergency Medicine. 2010; 55(3):235 246. [DOI:10.1016/j.annemergmed.2009.07.024] [PMID] [PMCID]

[16] Sampalis JS, Denis R, Lavoie A, et al. Trauma care regionalization: A process-outcome evaluation. The Journal of Trauma. 1999; 46:56581. [DOI:10.1097/00005373-199904000-00004] [PubMed] [PMID]

[17] Samplais JS, Lavoie A, Williams JI, Mulder DS, Kalina M. Impact of on-site care, prehospital time, and level of inhospital care on survival in severely injured patients. The Journal of Trauma. 1993; 34:252-61. [DOI:10.1097/00005373-199302000-00014] [PubMed]

[18] Dinh MM, Bein K, Roncal S, Byrne CM, Petchell J, Brennan J. Redefining the golden hour for severe head injury in an urban setting: the effect of prehospital arrival times on patient outcomes. International Journal of the Care of the Injured. 2013; 44(5):606-10. [DOI:10.1016/j.injury.2012.01.011] [PMID]

[19] Becker LR, Zaloshnja E, Levick N, Li G, Miller TR. Relative risk of injury and death in ambulances and other emergency vehicles. Accident Analysis \& Prevention. 2003; 35(6):941-48. [DOI:10.1016/ S0001-4575(02)00102-1] [PubMed]

[20] Davis DP, Hoyt DB, Ochs M, Fortlage D, Holbrook T, Marshall LK, Rosen $P$. The effect of paramedic rapid sequence intubation on outcome in patients with severe traumatic brain injury. The Journa of Trauma: Injury, Infection, and Critical Care. 2003; 54(3):444-53. [DOI:10.1097/01.TA.0000053396.02126.CD] [PMID] 